\title{
Differences in motor performances of children attending or not attending nursery school in Sénégal
}

\author{
E. BÉNÉFICE and A. BÂ* UR 'Condition d'Amélioration des Situations Nutritionnelles' \\ Institut Français de Recherche Scientifique pour le Développement en Coopération \\ (ORSTOM); Dakar and *Centre de Récupération et Education Nutritionnelle (CREN) \\ 'Terre des Hommes', Thiès, Sénégal
}

Accepted for publication 11 April 1994

Summary This study reports the results of motor performance measurements of Senegalese children aged 3.5-5.5 years. A total of 69 children were studied, of whom 30 were from a town and were attending a nursery school, while 39 were from rural areas and did not attend school. The tests were administered three times at 6 months intervals. The children were divided into two age groups: younger group (less than 4.5-years-old) and older group (more than 4-5-years-old). They had physical growth inferior to the international reference. In the successive tests carried out over one year, the children showed progress, while the difference in sex was insignificant. The younger group of urban origin performed better than their rural counterparts in tests of imitation, coordination, precision of movements, running, and balancing. There was less difference in older children according to their origin, however, the urban children had better physical growth and developed a stronger hand grip than their rural counterparts. The usefulness of nursery school as a vehicle for nutritional assistance and motor stimulation of underprivileged children has been emphasized.

Keywords motor performance nursery school children physical growth hand grip

\section{INTRODUCTION}

Improvement and development of motor performances are characteristics of

Correspondence: Dr E. Bénéfice, Laboratoire de Nutrition Tropicale, Centre ORSTOM BP 5045, 34032 Montpellier Cedex 1, France.

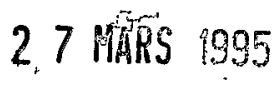

O.R.S.T.0.M. Fonds Documentaire

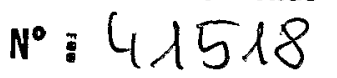

ex 1 
growing children. Motor development is a continuous process determined by neuro-muscular maturation, physical growth, body composition, and effects of previous and present experiences of the children (Malina \& Bouchard 1991). This process is under genetic control (regulation of growth and maturation) but can also be modified by environmental factors, as well as by learning, and by experience provided by children's surroundings (Haywood 1986).

In Africa, the study of psychomotor development of young children has tended to show advancement of African children in the stages of motor development in their first year (Geber 1956), however, these studies have been criticized due to possible faults in the method used and the protocols followed (Warren 1972). Super (1976) has demonstrated that he could show an advance in motor skills if these were taught and practiced regularly. It seems that advances in African children could be proven in certain tasks such as sitting without support, standing without support or walking alone, but not for other transitional activities such as 'roll over' or 'pull self to stand' (Iloeje, Obiekwe \& Kaine 1991). However, one does not know if this advance in psychomotor development is maintained in the course of ultimate development of the children. In fact, there are hardly any studies concerning the motor performances in African pre-school children. According to Toriola and Igbokwe (1986), Nigerian children living in urban environments who were relatively privileged, were very close or slightly: inferior in performance to Western children studied by Morris et al. (1982). In Sénégal, the children living in rural areas were clearly inferior to European children; this could be explained by the differences in growth and body composition (Bénéfice 1992).

The living condition of African children seems to be an important determinant of growth and development. The present study compared the development of the basic motor functions in Sénégalese children of the same ethnic origin but having different lifestyles.

\section{METHODS}

A total of 69 children ( 30 boys and 39 girls) aged between 3.5 and 5.5 years were studied. Thirty-nine children came from two separate villages in the central area of the country (Lambaye District) and 30 children were from a small coastal town (Mbour). The villagers were Muslim peasants whose ethnic origin was Wolof. They grew groundnuts and millet. Their income 
was meagre and the village did not have a school or health centre. The lifestyle of the children could be described as 'traditional' African and they belonged to the rural group in this study.

The children from Mbour town attended a nursery school where play and basic education were offered. This school was the beneficiary of a nongovernmental organization called the Christian Children's Fund which assisted with sanitation and food distribution; children received curdled milk, fish cake or chocolate bread twice a day, with a caloric value estimated to be 180-200 calories. These children were also Wolof by ethnic origin. Their social origin was modest, such as children of families of fishermen, vendors, labourers and peasants. Their lifestyle was very similar to those of rural children, although a small amount of regular family income supported them less precariously than the rural group. This group is known as an urban group.

All the children in this study were between 3.5 and 5.5 years old and were in apparently good health, and their parents approved the condition of the test. The administrative authorities, both medical and religious, were informed from the beginning of the study of the nature and the goal of the study. The children were examined three times in 1 year, at $6 \pm 1$ month interval. The examinations consisted of clinical examination to detect if the children suffered from an apparent illness which could interfere with the test: an anthropometric examination (weight measured with underclothes using an electronic scale with the precision of $100 \mathrm{~g}$ and the height measured standing upright with Harpenden(B) anthropometer) and motor function tests.

Motor tests were used to explore the basic acquisition in the domain of locomotor, non-locomotor and manipulation. They were elaborated from the proposed test by Hughes and Riley (1981), Connolly, Pharoah and Hetzel (1979) and Pařízková et al. (1984). They consisted of:

1 'Open and close hands'. This test is an indicator of sensory motor and coordination (Par̆ízková et al. 1984). The children had to reproduce the movement of the examiner after a demonstration after trying once. Four modalities were proposed (simultaneous closing and opening; opening left hand with right hand closed; opening right hand with left hand closed; alternate movements), each was evaluated separately ( $1=$ yes, $2=$ no).

2 Unimanual accuracy: number of bolts screwed in 2 min (bolts were 8 $\mathrm{mm}$ in diameter and $2 \mathrm{~cm}$ apart on a plate). 
3 Bimanual accuracy: number of coloured beads threaded in 2 min.

4 Standing balance: stand $10 \mathrm{~s}$ on one leg $(1=$ yes, $2=$ no $)$.

5 Forward roll: evaluated with a scale of 3 points $(1=\operatorname{good}, 2=$ small deviation, 3 = failure).

6 Heel and toe walking along $3 \mathrm{~m}$ line: each modality was noted on three points as above and the final point was the sum of two modalities, toe and heel walking.

7 Hopping on right foot, then on left foot on $3 \mathrm{~m}$ line. Each modality was marked on three points and the final point was the sum of two modalities.

8 Catching a tennis ball in three modalities: (a) a child catches a ball bounced by an adult two steps away; (b) the child bounces the ball in front of him or (c) the child catches a ball thrown up in his direction. Each modality was graded $1=$ yes, $2=$ no. The final score was the sum of the three modalities.

Finally the children had to perform:

$120 \mathrm{~m}$ dash (chronometer with the accuracy of $1 / 10 \mathrm{~s}$ )

2 Long jumping with the feet joined and the distance was measured from the tip of the toes to the heel in $\mathrm{cm}$. The best of three trials was taken.

3 Maximum hand grip strength measured by pressing a pear in leather connected to a manometer (Vigorimeter Martin ${ }^{\circledR}$, Tuttlingen, Germany). The children did three trials with the right hand, then with the left hand. The best were taken. The final result was the sum of the best score of the right and left hand. The unit of measure was the bar.

In the system of the quotation, the best score is 1 (success) and the worst is 2 or 3 . The scores were treated as the continuous quantitative variables. The analysis was performed by the BMDP package (BMDP Statistical Software Inc., Los Angeles, California, USA, 1988) by using analysis of variance on repeated measurements and analysis of covariance (Snedecor \& Cochran 1984).

The examinations were performed outdoors in the presence of a mother or close relative of the children. They were done in the same order by the authors aided by the same assistants.

\section{RESULTS}

In the course of the study the children regularly grew and gained weight; 
there was no difference between sex in these measurements. To facilitate the comparisons, anthropometric values are expressed in standard score for the age and the sex ( $z$-score) of the National Centre for Health Statistics (NCHS) which are also World Health Organization reference standards (WHO 1983). The average score of the height in the younger group (under 4.5 years at time of entry to the study) was -0.38 and for weight -0.80 . In the older group (more than 4.5 years at the time of entry to the study), the average $z$-score was -0.35 for height and -0.58 for weight. No variation was observed with the passage of time. Therefore, these children had their average height and weight below the median of the international reference population.

Table 1 presents the summary of the comparisons of the scores obtained by the girls and boys in the motor tests in three sessions. The children were divided into two groups to avoid an age bias between the younger group $(<4.5$ years) and the older group ( $>4.5$ years). Improvement in performances with the progression of the time is seen with all the tests except the test of catching a ball, and open/close hands in the younger group. The girls in the younger group attained a better score than the boys in open/close hands and walking on toes/heels. On the other hand, the boys in the older group were better at forward rolling, catching a ball and running than the girls. For the same age group, the difference in the origin,

TABLE 1 Results of analysis of variance for comparing mean scores of motor skills in two age-groups according to sex and visits

\begin{tabular}{|c|c|c|c|c|}
\hline & \multicolumn{2}{|c|}{$\begin{array}{l}\text { Group } 1 \text { (Age }<4.5 \text { years) } \\
\text { (boys } n=13 \text {; girls } n=20 \text { ) }\end{array}$} & \multicolumn{2}{|c|}{$\begin{array}{l}\text { Group } 2 \text { (age }>4.5 \text { years) } \\
\text { (boys } n=17 ; \text { girls } n=19 \text { ) }\end{array}$} \\
\hline & $\begin{array}{l}\mathrm{F} \text { (gender) } \\
\text { d.f. }(1,31)\end{array}$ & $\begin{array}{l}F \text { (visit) } \\
\text { d.f. }(2,62)\end{array}$ & $\begin{array}{l}F \text { (gender) } \\
\text { d.f. }(1,34)\end{array}$ & $\begin{array}{c}\text { F (visit) } \\
\text { d.f. }(2,68)\end{array}$ \\
\hline \multicolumn{5}{|l|}{ Motor skills } \\
\hline Open hands/close hands & $4 \cdot 2^{*}$ & $2 \cdot 0$ & $0 \cdot 3$ & $3 \cdot 1 *$ \\
\hline Unimanual accuracy & $1 \cdot 1$ & $28 \cdot 0 * * * * *$ & 0.06 & $22.5 * * * *$ \\
\hline Bimanual accuracy & $0 \cdot 2$ & $3 \cdot 8 *$ & $2 \cdot 2$ & $6 \cdot 5 * * *$ \\
\hline Standing balance & $2 \cdot 3$ & $11 \cdot 9 * * *$ & 0.2 & $7 \cdot 0 * * * *$ \\
\hline Forward roll & 0.2 & $36.9 * * *$ & $4 \cdot 3 *$ & $19 \cdot 3^{* * * *}$ \\
\hline Heel and toe walking & $4 \cdot 0^{*}$ & $1 \cdot 6^{*}$ & 0.04 & $6 \cdot 5 * *$ \\
\hline Hopping & $2 \cdot 6$ & $47.9 * * *$ & 1.7 & $9 \cdot 2^{* * *}$ \\
\hline Catching a ball & 0.0 & $1 \cdot 3$ & $4.8^{*}$ & $0 \cdot 6$ \\
\hline Hand grip strength & 0.6 & $9.2 * * *$ & 0.4 & $19 \cdot 0^{* * * * *}$ \\
\hline $20 \mathrm{~m}$ dash & $0 \cdot 0$ & $41 \cdot 8 * * *$ & $3 \cdot 8^{*}$ & $28 \cdot 1^{* * * *}$ \\
\hline Jumping & 0.2 & $12 \cdot 5 * * * *$ & $2 \cdot 8$ & $27.8 * * * *$ \\
\hline
\end{tabular}

$* P<0.05 ; * * P<0.01 ; * * * P<0.001$. 
TABLE 2. Comparison of motor skills between urban children and rural children in the younger group $(<4.5$ years at the beginning of study)(a)

\begin{tabular}{|c|c|c|c|c|}
\hline \multicolumn{2}{|l|}{ Motor skills } & \multirow{2}{*}{$\frac{\text { Adjusted mean }}{6.06}$} & \multirow{2}{*}{$\begin{array}{l}\text { SEM } \\
0 \cdot 15\end{array}$} & \multirow{2}{*}{$\frac{t}{3 \cdot 4 * * * *(b)}$} \\
\hline Open hands/close hands & Rural $(n=45)$ & & & \\
\hline (score) & Urban $(n=61)$ & $5 \cdot 36$ & $0 \cdot 13$ & \\
\hline Unimanual accuracy & Rural & $3 \cdot 20$ & 0.21 & $5 \cdot 6^{* * * * *}$ \\
\hline (number of bolts) & Urban & $4 \cdot 78$ & 0.18 & \\
\hline Bimanual accuracy & Rural & $12 \cdot 79$ & $0 \cdot 65$ & $2 \cdot 4 * *$ \\
\hline (number of beads) & Urban & $10 \cdot 64$ & 0.56 & \\
\hline Standing balance & Rural & 1.68 & 0.07 & 1.5 \\
\hline (score) & Urban & 1.54 & 0.05 & \\
\hline Forward roll & Rural & $2 \cdot 31$ & $0 \cdot 16$ & $0 \cdot 3$ \\
\hline (score) & Urban & $2 \cdot 25$ & 0.13 & \\
\hline Heel and toe walking & Rural & 3.71 & $0 \cdot 18$ & $2 \cdot 1 * *$ \\
\hline (score) & Urban & 3.06 & $0 \cdot 16$ & \\
\hline Hopping & Rural & $5 \cdot 20$ & 0.21 & $2 \cdot 9 * * *$ \\
\hline (score) & Urban & 4.42 & 0.18 & \\
\hline Catching a ball & Rural & $5 \cdot 57$ & $0 \cdot 11$ & 0.9 \\
\hline (score) & Urban & 5.43 & 0.09 & \\
\hline Hand grip strength & Rural & 0.48 & $0 \cdot 01$ & 0.5 \\
\hline (bar) & Urban & 0.49 & $0 \cdot 01$ & \\
\hline $20 \mathrm{~m}$ dash & Rural & 7.06 & $0 \cdot 12$ & $2 \cdot 6^{* * *}$ \\
\hline (s) & Urban & $6 \cdot 63$ & $0 \cdot 10$ & \\
\hline Jumping & Rural & $63 \cdot 1$ & $3 \cdot 2$ & $0 \cdot 3$ \\
\hline$(\mathrm{cm})$ & Urban & $61 \cdot 6$ & $2 \cdot 8$ & \\
\hline
\end{tabular}

(a) mean scores are controlled for age, gender and visit number by analysis of covariance.

(b) $* P<0.05$; ** $P<0.01$; *** $P<0.001$.

rural or urban and its effect of the test results was studied. Table 2 demonstrates the results of the comparisons in the younger group after the adjustment for, age and progression of time. The slope of the regression line was the same which eliminated the possibility of interaction. The urban children were better than the rural children in close/open hands, unimanual precision, heel/toe walking, hopping and running. On the other hand, the rural children were better at threading the beads. The older children in the urban had the best results at open hands/close hands, unimanual accuracy and hand grip strength (Table 3).

The comparison of anthropometric parameters showed that there was no difference in the weight and height among different origins in the younger group, while in the older group, urban children were significantly taller (height $=114.0 \pm 3.3 \mathrm{~cm}$ vs $109.5 \pm 3.3 \mathrm{~cm}, t=6.1, P<0.00$ ) and heavier (weight $=18.6 \pm 1.5 \mathrm{~kg}$ vs $17.7 \pm 1.5 \mathrm{~kg}, t=2.5, P<0.01$ ) than the rural counterparts. 
TABLE 3. Comparison of motor skills between urban children and rural children in the older group ( $>4.5$ years at the beginning of study) ${ }^{(a)}$.

\begin{tabular}{|c|c|c|c|c|}
\hline \multicolumn{2}{|l|}{ Motor skills } & \multirow{2}{*}{$\frac{\text { Adjusted mean }}{5.73}$} & \multirow{3}{*}{$\begin{array}{l}\text { SEM } \\
0.12 \\
0.19\end{array}$} & \multirow{2}{*}{$\frac{t}{3 \cdot 3 * * * *(b)}$} \\
\hline Open hands/close hands & Rural $(n=72)$ & & & \\
\hline (score) & Urban $(n=29)$ & 4.94 & & \\
\hline Unimanual accuracy & Rural & $4 \cdot 40$ & 0.20 & $3.0 * * * *$ \\
\hline (number of bolts) & Urban & $5 \cdot 47$ & 0.32 & \\
\hline Bimanual accuracy & Rural & $15 \cdot 56$ & 0.58 & $1 \cdot 3$ \\
\hline (number of beads) & Urban & 14.04 & 0.92 & \\
\hline Standing balance & Rural & 1.25 & 0.04 & 0.0 \\
\hline (score) & Urban & 1.24 & 0.07 & \\
\hline Forward roll & Rural & $2 \cdot 01$ & 0.12 & 0.7 \\
\hline (score) & Urban & $2 \cdot 19$ & $0 \cdot 20$ & \\
\hline Heel and toe walking & Rural & 2.79 & 0.13 & $1 \cdot 6$ \\
\hline (score) & Urban & 2.39 & 0.21 & \\
\hline Hopping & Rural & $3 \cdot 61$ & $0 \cdot 18$ & $0 \cdot 8$ \\
\hline (score) & Urban & $3 \cdot 32$ & 0.28 & \\
\hline Catching a ball & Rural & $4 \cdot 64$ & $0 \cdot 14$ & $0 \cdot 0$ \\
\hline (score) & Urban & $4 \cdot 64$ & 0.22 & \\
\hline Hand grip strength & Rural & 0.60 & 0.01 & $2 \cdot 2^{*}$ \\
\hline (bar) & Urban & 0.67 & 0.02 & \\
\hline $20 \mathrm{~m}$ dash & Rural & 6.23 & 0.09 & $0 \cdot 6$ \\
\hline (s) & Urban & $6 \cdot 35$ & 0.15 & \\
\hline Jumping & Rural & 77.7 & $2 \cdot 2$ & $0 \cdot 6$ \\
\hline$(\mathrm{cm})$ & Urban & $75 \cdot 2$ & $3 \cdot 5$ & \\
\hline
\end{tabular}

(a) mean scores are controlled for age, gender and visit number by analysis of covariance.

(b) $* P<0.05 ; * * P<0.01 ; * * * P<0.001$.

\section{DISCUSSION}

The results of the study show a development of motor skills of the children in the course of the study. The tests used in the study were simple, reproducible and clear to interpret. Seeing the children three times allowed quality control of the results obtained.

There was little genders difference except of the older group in running and catching a ball. In Nigeria, Toriola and Igokwe (1986) noted a significant advantage boys had over girls in jumping and running, but not in balancing. In Sénégal the difference in sex was only noted in children over 5.5 years in running and throwing (Bénéfice 1992). In 3-6-year-old children, changes due to the age were more pronounced than in sex. The 
results obtained from the present study thus conforms to the studies done elsewhere.

The difference linked to the origin was more marked in younger children than in older children in the tests of precision of the movements, coordination and speed. Hopping and heel/toe walking called for muscular force, balance in movement and co-ordination (Rigal 1985). In general, the urban group scored better in these tests than the rural group. This can be explained by the positive effect of attending school which encourages attention, repetition of movements and imitation of the teacher, which was the case in open/close hands. The group play and dance practised at school could favour the speed and better control of muscles in locomotor tests; to these students competition is familiar. The discrepancy in the precision test in uni- and bi-manual activity is probably due to a cultural factor. In the villages, young girls are used to thread beads to make jewellery, for hair braiding and necklaces to sell.

The older children constitute a homogenous group according to the criteria of the origin. The rural group caught up to the urban group but slowness persisted in imitation and repetition of the movement and unimanual accuracy. The urban group was capable of developing a superior force; it might be due to the advantage of their higher weight and height. The children who were in their second year of school could accumulate a nutritional advantage which would be translated into better growth and better strength than the rural children. Thus, it seems that there is a separation of effect in time: the young urban group developed first their functional capacity, then better physical growth than their rural counterparts. There was no difference in balancing, catching a ball or jumping according to origin. The basic skills in task performance developed in the same rhythm in both groups probably due to the similar rearing practices during infancy. In Sénégal, the children are carried on their mother's back for a long time and it was demonstrated that a vestibular stimulation in an infant improves gross motor skills (Clark, Kreutzberg \& Chee 1977).

This study suggests that motor development is influenced by the environment where children are raised. The proposed learning was in fact summarized and delivered by the child minders without real training. Elaborated learning could certainly improve the proficiency in motor skills in the children. Malnutrition associated with poverty is a widespread condition in Africa. It is also associated with intellectual behavioural deficits (Stanfield 1993). This deficit would not have as definite an effect as 
one thinks (Colombo, de la Parra \& Lopez 1992). Thus, it was demonstrated that children, previously severely malnourished, developed quickly and maintained the benefit of nutritional recovery when they were stimulated (Granham-McGregor, Schofield \& Powell 1987). Nursery school would be a place of surveillance and help for children who are exposed to the risks. Unfortunately, pre-school education in Sénégal is practically non-existent and it is not a high priority area in education programmes. Nurseries functioning at a very low cost as in the present study offer possibilities of wakening and stimulation, as well as the opportunity for nutritional and sanitary interventions; such nurseries could be an excellent place of assistance for underprivileged children.

\section{ACKNOWLEDGEMENTS}

This study was supported by the Conditions d'Amélioration des Situations Nutritionnelles Research Unit of the ORSTOM. The authors thank all the children of Lambaye and Mbour who participated in this study. Thanks are also due to our field assistants Modou Mbow, Daouda Ndiaye and Olivier Bages-Limoges who was an undergraduate research assistant. We are grateful to Mr Seydou Diao and to all the staff of 'Mme Elisabeth Diouf' nursery school at Mbour for their kind assistance.

\section{REFERENCES}

Bénéfice E. (1992) Growth and motor performance of healthy Sénégalese preschool children. American Joumal of Human Biology 4, 717-728

Clark D., Kreutzberg J. \& Chee F. (1977) Vestibular stimulation influence on motor development in infants. Science 196, 1228-1229

Colombo M., de la Parra A. \& Lopez I. (1992) Intellectual and physical outcome of children undernourished in early like is influenced by later environmental conditions. Developmental Medicine and Child Neurology 34, 611-622

Connolly K., Pharoah P. \& Hetzel B. (1979) Fetal iodine deficiency and motor performance during childhood. Lancet 2, 8153, 1149-1151

Geber M. (1956) Développement psycho-moteur de l'enfant africain. Courrier 6, 17-27

Grantham-McGregor S., Schofield W. \& Powell C. (1987) Development of severely malnourished children who received psychosocial stimulation: six-year follow-up. Pediatrics 79, 247-254

Haywood K. (1986) Life Span Motor Development. Human Kinetics, Champaign, Illinois, pp. 73-140

Hughes J. \& Riley A. (1981) Basic motor assessment: tool for use with children having minor motor dysfunction. Physical Therapy 61, 503-511

Iloeje S., Obiekwe V. \& Kaine W. (1991) Gross motor development of Nigerian children. Annals of Tropical Paediatrics 11, 33-39

Malina R. \& Bouchard C. (1991) Growth, Maturation, and Physical Activity. pp. 171-204 
Morris A., Williams J., Aywater A. \& Wilmore J. (1982) Age and sex differences in motor performance of 3 through 6 year old children. Research Quarterly for Exercise and Sport 53, 214-221

Pă̌ízková J., Adamec A., Berdychová J., Čermák J., Horna J. \& Teplý Z. (1984) Growth, Fitness and Nutrition in Preschool children. Charles University, Prague

Rigal R. (1985) Motricité Humaine: Fondements et Applications Pédagogiques. Vigot, Paris

Stanfield J. (1993) Some aspects of the long-term of malnutrition on the behaviour of children in the third world. Proceedings of the Nutrition Society 52, 201-210

Snedecor G. \& Cochran W. (1984) Méthodes statistique. (Boelle H., Camhaji E., trans). Association de Coordination Technique Agricole, Paris

Super C. (1976) Environmental effects on motor development: the case of 'African infant precocity'. Developmental Medicine and Child Neurology 18, 561-567

Toriola A. \& Igbokwe N. (1986) Age and sex differences in motor performance of pre-school Nigeriam children. Journal of Sports Sciences 4, 219-227

Warren N. (1972) African infant precocity. Psychological Bulletin 78, 353-367

World health Organization (1983) Measuring Change in Nutritional Status. Guidelines for assessing the nutritional impact of supplementary feeding programmes for vulnerability groups. WHO, Geneva 